\title{
Retrospective analysis underestimates neurological deficits in complex spinal deformity surgery: a Scoli-RISK-1 Study
}

\author{
Michael P. Kelly, MD, MSc, ${ }^{1}$ Lawrence G. Lenke, MD, ${ }^{2}$ Jakub Godzik, MD, ${ }^{3}$ Ferran Pellise, MD, ${ }^{4}$ \\ Christopher I. Shaffrey, MD, ${ }^{5}$ Justin S. Smith, MD, PhD, ${ }^{5}$ Stephen J. Lewis, MD, ${ }^{6}$ \\ Christopher P. Ames, MD, ${ }^{7}$ Leah Y. Carreon, MD, MSc, ${ }^{8}$ Michael G. Fehlings, MD, PhD, ${ }^{9}$ \\ Frank Schwab, MD, ${ }^{10}$ and Adam L. Shimer, MD ${ }^{11}$
}

\begin{abstract}
1Department of Orthopedic Surgery, Washington University, Saint Louis, Missouri; ${ }^{2}$ Department of Orthopedic Surgery, Columbia

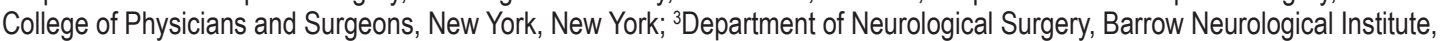
Phoenix, Arizona; ${ }^{4}$ Orthopedic Surgery and Traumatology, Universitat Autonoma de Barcelona, Barcelona, Spain; ${ }^{5}$ Department of Neurological Surgery, University of Virginia School of Medicine, Charlottesville, Virginia; ${ }^{6}$ Division of Orthopaedics, University of Toronto, Ontario, Canada; ' ${ }^{D}$ epartment of Neurological Surgery, University of California, San Francisco, California; ${ }^{8}$ Norton Leatherman Spine Center, Louisville, Kentucky; ${ }^{9}$ Department of Neurological Surgery, University of Toronto, Ontario, Canada; ${ }^{10}$ Department of Orthopedic Surgery, Hospital for Special Surgery, New York, New York; and ${ }^{11}$ Department of Orthopedic Surgery, University of Virginia School of Medicine, Charlottesville, Virginia
\end{abstract}

OBJECTIVE The authors conducted a study to compare neurological deficit rates associated with complex adult spinal deformity (ASD) surgery when recorded in retrospective and prospective studies. Retrospective studies may underreport neurological deficits due to selection, detection, and recall biases. Prospective studies are expensive and more difficult to perform, but they likely provide more accurate estimates of new neurological deficit rates.

METHODS New neurological deficits were recorded in a prospective study of complex ASD surgeries (pSR1) with a defined outcomes measure (decrement in American Spinal Injury Association lower-extremity motor score) for neurological deficits. Using identical inclusion criteria and a subset of participating surgeons, a retrospective study was created (rSR1) and neurological deficit rates were collected. Continuous variables were compared with the Student t-test, with correction for multiple comparisons. Neurological deficit rates were compared using the Mantel-Haenszel method for standardized risks. Statistical significance for the primary outcome measure was $p<0.05$.

RESULTS Overall, 272 patients were enrolled in pSR1 and 207 patients were enrolled in rSR1. Inclusion criteria, defining complex spinal deformities, and exclusion criteria were identical. Sagittal Cobb measurements were higher in pSR1, although sagittal alignment was similar. Preoperative neurological deficit rates were similar in the groups. Three-column osteotomies were more common in pSR1, particularly vertebral column resection. New neurological deficits were more common in pSR1 (pSR1 17.3\% [95\% Cl 12.6-22.2] and rSR1 9.0\% [95\% Cl 5.0-13.0]; $p=0.01$ ). The majority of deficits in both studies were at the nerve root level, and the distribution of level of injury was similar.

CONCLUSIONS New neurological deficit rates were nearly twice as high in the prospective study than the retrospective study with identical inclusion criteria. These findings validate concerns regarding retrospective cohort studies and confirm the need for and value of carefully designed prospective, observational cohort studies in ASD.

https://thejns.org/doi/abs/10.3171/2016.12.SPINE161068

KEY WORDS adult deformity; neurological deficit; complication

A DULT spinal deformity (ASD) surgery has become increasingly complex, with patients with severe deformities undergoing 3-column osteotomies (3COs), such as pedicle subtraction osteotomy or vertebral column resection (VCR). ${ }^{1,2,4-6,9-11,13-16,20,22,32}$ Complication rates exceeding $50 \%$ have been reported in this patient population. ${ }^{15-17,29,30}$ Neurological deficits, such as weakness and paralysis, are less common and have been estimated at $10 \%$ or lower. ${ }^{8,10,21}$ These data come largely from retrospective cohort studies and are subject to a number of

ABBREVIATIONS ASA = American Society of Anesthesiologists; $A S D=$ adult spinal deformity; $A S I A=$ American Spinal Injury Association; EBL = estimated blood loss; PSR1 = the prospective study; $r S R 1=$ the retrospective study; $V C R=$ vertebral column resection; $3 C O=3$-column osteotomy.

SUBMITTED September 7, 2016. ACCEPTED December 30, 2016.

INCLUDE WHEN CITING Published online May 5, 2017; DOI: 10.3171/2016.12.SPINE161068. 
biases, including recall, patient selection, and treatment biases. ${ }^{20}$ As a result, rates of complications may be underreported and significant associations may be misrepresented, despite the use of multivariate regression analyses. Inaccurate data impair patient counseling and the informed decision-making process, as patients may choose to undergo these complex procedures without full appreciation of the risks involved.

Prospective registries of patients with ASD have been established to overcome the shortcomings of retrospective studies. In such studies, standardized data collection forms are used, although no formal neurological examination training is performed. Several such registries, including those of the International Spine Study Group and the Spinal Deformity Study Group, have reported $15.5 \%$ and $2 \%$ acute neurological deficit rates, respectively. ${ }^{19,29}$ The spinal deformities collected by the International Spine Study Group registry are heterogeneous, with a mix of mild, moderate, and severe deformities, and with a similarly heterogeneous cohort of surgical techniques. The absence of clearly defined outcome measures specific to neurological injury is a limitation of these types of observational cohorts, as prespecified hypotheses aid study design, data collection, and data analysis. ${ }^{3}$

Prospective studies, with predefined outcomes, are less likely to offer inaccurate estimates and conclusions as they avoid the biases of retrospective studies and patient registries. ${ }^{18,25,28}$ The Arbeitgemeinschaft für Osteosynthesefragen (AO) Spine Scoli-RISK-1 study, a prospective, observational, multicenter study, was established to specifically evaluate the neurological complications associated with surgical correction of ASD. ${ }^{26}$ A tandem, retrospective study was also created with identical inclusion criteria and similar data collection..$^{21}$ The aim of the present study was to compare the rates of neurological deficit found in the prospective study (pSR1) with those of a retrospective series of patients meeting Scoli-RISK-1 eligibility criteria (rSR1). Given the aforementioned biases associated with retrospective studies, we hypothesized that the rSR1 group would have fewer reported neurological deficits than the pSR1 group. To our knowledge, there are no studies evaluating the influence of study design on reported complication rates in spinal deformity surgery. We hope that this study emphasizes the importance of funding and performing prospective, observational cohort studies.

\section{Methods \\ Patient Selection}

Fifteen centers participated in the prospective, observational cohort as part of the Scoli-RISK-1 study (i.e., pSR1). Inclusion criteria were patients' ages 18-80 years, with a primary coronal or sagittal plane Cobb measurement $\geq$ 80 . Any patients undergoing a $3 \mathrm{CO}$-type procedure $(3 \mathrm{CO}$, VCR, or pedicle subtraction) were eligible. Patients with congenital anomalies of the spine treated with any osteotomy (3CO or posterior column) and revision spine surgeries treated with any osteotomy were included. Finally, any patients with an ossified ligamentum flavum or posterior longitudinal ligament treated with a decompression as part of their reconstruction or preexisting myelopathy due to the deformity were included.

Patients were excluded if they had a history of recent substance dependency, psychosocial disturbance, active malignancy, active bacterial infection (systemic or local), recent (within 3 months) trauma, prior paraplegia, or were pregnant or nursing. Patients unlikely to comply with follow-up were excluded from enrollment in pSR1. To create a comparative, retrospective cohort 5 centers participating in the Scoli-RISK-1 trial used identical inclusion and exclusion criteria to identify eligible patients from June 2009 to June 2011.

\section{Prospective Data Collection}

Standardized data collection sheets were distributed to all centers participating in pSR1. Preoperative data collected included age, sex, body mass index, primary diagnosis with Cobb and alignment measurements ( $\mathrm{C}-7$ coronal and sagittal), and any history of surgeries. Operative data collected included number of levels treated, osteotomies performed and type, estimated blood loss (EBL), and total operative time. Planned staged procedures were recorded. Complications were defined a priori and were collected in a prospective manner for pSR1. A full neurological examination (American Spinal Injury Association [ASIA]) was performed at a preoperative visit for patients enrolled in pSR1. At the 6-week follow-up visit, a repeat ASIA examination was performed. Any decrement in ASIA lowerextremity motor score was recorded as a new neurological deficit. ASIA motor scores were recorded with the level of injury. The level of injury was categorized as follows: spinal cord level (above L-1), nerve root level (L1-S1), and cauda equina/conus medullaris level (below S-1). All investigators performing physical examinations in pSR1 were trained and certified by ASIA. This improves the validity and interpreter reliability of examinations. ${ }^{12}$

\section{Retrospective Data Collection}

Data collection sheets mirroring pSR1 were created for rSR1 and distributed to participating sites. Medical records, including in-hospital notes, were reviewed and appropriate perioperative data collected. Medical records were reviewed for evidence of a new neurological deficit. Physical examinations were compared preoperatively and postoperatively and any decrement noted as a new neurological deficit. Operative records were reviewed for evidence of intraoperative neurophysiological monitoring alerts with concomitant documentation of neurologicals deficit and for neurological status at the end of surgery. Finally, communication records, including telephone calls, were reviewed for evidence of new neurological deficits and other complications. The level of injury was taken from the medical record and categorized as spinal cord level, nerve root level, and cauda equina/conus medullaris level.

\section{Statistical Analysis}

Continuous data were compared using unpaired t-tests and categorical data compared using chi-square and Fisher's exact test. Specifically, rates of reported new neuro- 
logical deficits were compared between groups using the chi-square test. The Wilcoxon rank-sum test was used to examine differences in American Society of Anesthesiologists (ASA) score and neurological deficit distributions. Statistical significance was defined as $p<0.05$ for the primary outcome measure of new neurological deficit. To avoid Type I error, a Bonferroni correction was used for all other comparisons $(\mathrm{p}<0.004$ [0.05/14]). To account for disproportionate VCR in the prospective cohort, standardized risks were calculated using the Mantel-Haenszel method. IBM SPSS Statistics v20 (SPSS Inc.) was used for all analyses.

\section{Results}

Two hundred seventy-two patients were enrolled at 15 centers as part of the Scoli-RISK-1 trial and comprised the pSR1 group. Two hundred seven patients were identified in the surgical records of 5 centers participating in ScoliRISK-1 with surgical indications that met the criteria for pSR1. These patients comprised the retrospective cohort (rSR1). Mean age and sex distribution were similar in the 2 groups (Table 1). Preoperative neurological deficits were more common in the rSR1 group. Maximum measured coronal deformity was greater in rSR1, although sagittal plane measurements were similar.

Patients in the prospective study underwent longer surgeries (448 mins vs 403 mins, $p=0.001$ ), had greater EBL
(2639 $\mathrm{ml}$ vs $1967 \mathrm{ml}$, respectively; $\mathrm{p}=0.000$ ), and had more levels fused (12.5 vs 10.5 , respectively; $\mathrm{p}<0.001$ ) (Table 2). Three-column osteotomies, VCR in particular, were more common in pSR1 (23\% [63/272] in pSR1vs 9\% [19/207] in rSR1; $p=0.004)$. New neurological deficits were more common in pSR1 than in rSR1 $(17.3 \%$ [95\% CI $12.6 \%-22.2 \%$ ] vs $9.0 \%$ [95\% CI $5.0 \%-13.0 \%$ ]; $p=0.01$ ). The locations of new neurological deficits were similar in the 2 groups, with nerve root level deficits being most common (Table 2).

\section{Discussion}

While the risks associated with ASD surgery have been previously described, few studies have been performed in a prospective fashion with an a priori focus on neurological risk., ${ }^{1,4-6,10,13-16,22,32}$ As the majority of the new neurological deficit rates are obtained from retrospective analyses, the studies are inherently limited by their methodology; selection bias, recall bias, and cognitive dissonance all predispose such studies to an underreporting of the true risk associated with surgery and thereby limit the appropriate counseling of patients and families. A large, multicenter, prospective observational study was designed with the expressed goal of tracking neurological risk in complex ASD reconstructive surgery; a secondary arm of the study was a retrospective review of patients from participating centers with identical inclusion criteria, to

TABLE 1. Preoperative demographic data

\begin{tabular}{|c|c|c|c|}
\hline Variable & Prospective SR-1 $(n=272)$ & Retrospective SR-1 $(n=207)$ & p Value \\
\hline Age in yrs, mean (SD) & $56.9(15.3)$ & $55.5(15.8)$ & 0.329 \\
\hline Male, no. & $89(32.7 \%)$ & $68(32.9 \%)$ & 0.922 \\
\hline Height in $\mathrm{cm}$, mean (SD) & $161.3(13.1)$ & $159.5(11.8)$ & 0.121 \\
\hline Weight in $\mathrm{kg}$, mean (SD) & $70.6(20.5)$ & $70.4(24.4)$ & 0.922 \\
\hline $\begin{array}{l}\text { ASA score, no. } \\
\quad 1 \\
2 \\
3 \\
4\end{array}$ & $\begin{array}{c}9(3.3 \%) \\
143(52.8 \%) \\
118(43.5 \%) \\
1(0.4 \%)\end{array}$ & $\begin{array}{c}13(7.0 \%) \\
102(54.6 \%) \\
64(34.2 \%) \\
8(4.3 \%)\end{array}$ & 0.256 \\
\hline $\begin{array}{l}\text { Preop motor deficit, no. } \\
\text { No } \\
\text { Yes } \\
\text { Missing }\end{array}$ & $\begin{array}{c}197(72.7 \%) \\
74(27.3 \%) \\
1\end{array}$ & $\begin{array}{c}134(64.7 \%) \\
72(34.8 \%) \\
1\end{array}$ & 0.088 \\
\hline Major coronal Cobb angle in degrees, no., mean (SD) & $257,28.2(26.3)$ & $207,44.1(34.3)$ & $<0.001$ \\
\hline Major sagittal Cobb angle in degrees, no., mean (SD) & $262,63.9(27.3)$ & $207,51.7(42.6)$ & $<0.001$ \\
\hline C-7 sagittal vertical axis in mm, no., mean (SD) & $222,100.8(100.8)$ & $207,93.5(79.5)$ & 0.408 \\
\hline $\begin{array}{l}\text { Prior spine surgery, no. } \\
\text { No } \\
\text { Yes } \\
\text { Missing }\end{array}$ & $\begin{array}{l}103(37.9 \%) \\
169(62.1 \%)\end{array}$ & $\begin{array}{c}47(24.2 \%) \\
147(71 \%) \\
13\end{array}$ & 0.002 \\
\hline $\begin{array}{l}\text { 3CO, no. } \\
\text { No } \\
\text { Yes } \\
\text { PSO } \\
\text { VCR }\end{array}$ & $\begin{array}{r}66(24.3 \%) \\
206(75.7 \%) \\
147(54.0 \%) \\
63(23.2 \%)\end{array}$ & $\begin{array}{c}75(36.2 \%) \\
132(63.8 \%) \\
113(54.6 \%) \\
19(9.2 \%)\end{array}$ & $\begin{array}{r}0.004 \\
0.906 \\
<0.001\end{array}$ \\
\hline
\end{tabular}

PSO = pedicle subtraction osteotomy.

Boldface type indicates statistical significance. 
TABLE 2. Intraoperative and perioperative data

\begin{tabular}{|c|c|c|c|}
\hline Variable & Prospective SR-1 ( $\mathrm{n}=272$ ) & Retrospective SR-1 ( $n=207$ ) & p Value \\
\hline Total op time in mins, mean (SD) & $448.5(164.4)$ & $403.5(127.9)$ & 0.001 \\
\hline EBL in ml, mean (SD) & $2639(2008.8)$ & $1967.3(1572.2)$ & $<0.001$ \\
\hline Total levels fused, mean (SD) & $12.2(3.9)$ & $10.5(4.4)$ & $<0.001$ \\
\hline Acute neurological deficit, ${ }^{*}$ no. & $44(17 \%)$ & $18(8.7 \%)$ & 0.009 \\
\hline No $3 \mathrm{CO}$ & 6 & 5 & \\
\hline PSO & 30 & 10 & \\
\hline VCR & 9 & 3 & \\
\hline Mantel-Haenszel standardized risk, \% (95\% Cl) & $17 \%(13 \%-22 \%)$ & $9 \%(5 \%-13 \%)$ & 0.01 \\
\hline Level of neurological deficit," no. & & & 0.114 \\
\hline None & 214 & 189 & \\
\hline Spinal cord & $9(3.4 \%) \dagger$ & $6(3.0 \%) \ddagger$ & \\
\hline Nerve root & $19(7.4 \%) \dagger$ & $9(4.3 \%) \ddagger$ & \\
\hline Cauda equina/conus medullaris & $5(1.9 \%) \dagger$ & $3(1.5 \%) \ddagger$ & \\
\hline Not recorded & $11(4.3 \%) \dagger$ & 0 & \\
\hline
\end{tabular}

compare the rates of neurological deficits reported in prospective and retrospective studies.

In the present study, an observational cohort of 272 patients undergoing ASD for major deformities at 15 centers revealed an overall new neurological deficit rate of $17.9 \%$ at 6 weeks postoperatively. A retrospective observational cohort from 5 participating centers, using identical inclusion and exclusion criteria, found a significantly lower rate of new deficits ( $8.7 \%$ as compared with $17.9 \%, \mathrm{p}=0.0016)$. Inclusion criteria were the same in the 2 cohorts and the small differences in deformity magnitude are unlikely to have affected neurological complication rates and selection bias should be minimized. Enrollment for the 2 groups was close in time, without significant advances in technology available in the prospective cohort, also supporting the similarity of surgeries performed. Finally, performance bias may have some role in the different rates reported, although the centers participating in the retrospective cohort study were among the highest-volume centers in the prospective arm. The observed discrepancy between methodologies in otherwise similar surgical groups highlights the dangers of studying discrete events such as neurological deficits in a retrospective manner.

The overall complications rates previously reported for ASD are high, exceeding 30\%.9,19,29 The variability in reported rates of neurological deficits after ASD reconstructions is impressive. Yang et al. presented a series of 35 consecutive patients undergoing pedicle $3 \mathrm{CO}$ for spinal deformity and reported one transient nerve root deficit, for a rate of $3 \% .{ }^{32}$ Ahn and colleagues reported a higher neurological deficit rate, $11 \%$, in 83 patients who underwent a variety of $3 \mathrm{CO}$ procedures for ASD. ${ }^{1}$ Similar to this rate, Buchowski et al. presented a consecutive series of patients who underwent $3 \mathrm{CO}$ and found a neurological deficit rate of $11 \% .^{10}$ This rate of nearly $10 \%$, with the majority of deficits being transient, has been presented elsewhere. ${ }^{22}$ The authors of other retrospective analyses have even reported series without any neurological deficits. ${ }^{23}$
As we have shown here, retrospective studies are subject to many biases, including recall bias and, as a result, likely underreport true complication rates. Prospective, observational registries have reported a wide range of neurological deficits, from $2 \%$ to $15.5 \% .^{19,29}$ The rate of new neurological deficits from a retrospective cohort presented here, $8.7 \%$, compares favorably with those previously published and commonly cited incidences. Prospective studies with a priori end points and predefined data collection techniques should not be subject to this bias and, as a result, report higher complication rates. The rates of most modern registry compare favorably with the rate in the prospective arm of the current study, supporting the value of carefully designed multicenter registries.

This study also supports the need for strict definitions of complications and evaluator training, particularly in regards to the detection of new neurological deficits. In the prospective study, all patients underwent preoperative and postoperative ASIA examinations to document motor function. All examiners were ASIA certified, increasing the reliability and validity of examination results. ${ }^{12}$ While all patients in the retrospective study were examined preoperatively and postoperatively, the outcome measurement was often a subjective adaptation of the ASIA examination, recorded in the medical record without a clearly defined format. As such, the prospective cohort was subject to examinations that more sensitive to change. The majority of deficits in the prospective group were small changes in lower-extremity strength, and these may have been ignored or inaccurately recorded in the retrospective cohort. Evaluators in the prospective cohort underwent formal ASIA training, which has been shown to improve the accuracy of the examination and classification. ${ }^{12}$ This lack of general standards of measurement has been cited before as a reason for error in retrospective reporting. ${ }^{27}$ Furthermore, this serves as a point of emphasis for future study as we seek to clearly define the rates of, and risk factors for, complications in ASD. This patient population 
is at high risk for perioperative complications and without strict, a priori outcomes measurements and assessments for each complication, we are likely to continue to underreport the true value and misrepresent risk factors to our patient population.

There are limitations to the present study, particularly regarding study design. The prospective study was composed of patients from 15 different centers, while the retrospective study was composed of patients from a subset of 5 centers. As such, the number of surgeons participating in pSR1 was greater than rSR1. Performance bias may be a concern when comparing the results of procedures performed by various surgeons. We believe, however, that the broader prospective group offers better data, as the data are more generalizable to adult deformity surgery as a whole. The results of a cohort including more surgeons likely lend external validity to the conclusions, as opposed to the internally valid conclusions of a smaller research group..$^{28}$ Furthermore, one would expect, with greater experience and dissemination of information, that neurological deficits would decline, rather than increase. While possible, it is unlikely that the rate of new neurological deficits has increased over time, thus implying that a flaw in retrospective data collection exists, such as recall bias or cognitive dissonance. In many cases, this would be deemed a limitation, but the purpose of this study was to confirm that such biases exist and contribute to significant underestimation of true neurological risk.

Selection bias is unlikely to have a significant confounding effect, as similar strict inclusion criteria were applied to each group. ASD is a heterogeneous disease, with a multitude of underlying pathologies and symptoms. The cohorts compared here are similar with respect to many important demographic variables, and all deformities were defined as "complex" by the definition from pSR-1. A small, likely clinically insignificant, difference exists between preoperative coronal and sagittal Cobb angle magnitudes. We believe the fact that inclusion criteria were identical and that demographic data were similar is evidence that these 2 cohorts are similar and comparable. Propensity weighting and matching has been proposed as a method to balance for imbalances in baseline data, to replicate random distribution as close as is possible. Propensity weighting, however, has been shown to increase imbalance and bias in observational cohorts. ${ }^{24}$ An ideal study would include retrospective analysis of the prospective cohort via medical record review; however, the recording of the ASIA examination in the record precludes such a study. We must emphasize that the patients studied here were treated for complex ASD and the findings may not extrapolate to other pathologies, such as degenerative cervical and lumbar conditions. Finally, we have found that 5 participating centers reported lower rates of neurological deficits in a retrospective cohort. Inaccurate data collection may be problematic within these 5 centers and is a limitation of multicenter research, further emphasizing the need for a priori outcomes and trained evaluators as used in pSR1.?

An emphasis on evidence-based practice and shared decision making requires accurate data, to allow for informed decision making by patients. The data presented here emphasize the need for well-designed prospective studies, with a priori defined outcomes measures, to estimate accurate values for outcomes in spine surgery. This is not to suggest that retrospective studies are of no value but rather the implication highlights their limitations in guiding surgical decision making and patient risk counseling..$^{20,31}$ Retrospective studies are valuable, as they are inexpensive to perform and use existing data. They are limited by the quality and availability of these data, as we have seen here, because the information gathered was not collected for research purposes. Prospective studies are intensive and often expensive to perform, and retrospective cohort studies are needed to guide study design to optimize prospective studies. Given their expense, the value of prospective observational cohorts must be recognized as randomized trials are often not feasible for chronic, debilitating musculoskeletal diseases.

\section{Conclusions}

In the current study, we demonstrate that a retrospective cohort study investigating neurological deficits after complex ASD reconstruction found a significantly lower rate of new neurological deficit than a prospective cohort. The prospective study reported a $17.8 \%$ neurological deficit rate, which is nearly twice the rate found in the retrospective study. This study underscores the need for prospective studies of ASD using discrete outcomes measures and evaluator education. As these studies are expensive to perform, support from funding agencies will be necessary as we seek to determine safety and effectiveness of ASD surgery.

\section{References}

1. Ahn UM, Ahn NU, Buchowski JM, Kebaish KM, Lee JH, Song ES, et al: Functional outcome and radiographic correction after spinal osteotomy. Spine (Phila Pa 1976) 27:13031311, 2002

2. Ali RM, Boachie-Adjei O, Rawlins BA: Functional and radiographic outcomes after surgery for adult scoliosis using third-generation instrumentation techniques. Spine (Phila Pa 1976) 28:1163-1170, 2003

3. Berger ML, Dreyer N, Anderson F, Towse A, Sedrakyan A, Normand SL: Prospective observational studies to assess comparative effectiveness: the ISPOR good research practices task force report. Value Health 15:217-230, 2012

4. Berven SH, Deviren V, Smith JA, Emami A, Hu SS, Bradford DS: Management of fixed sagittal plane deformity: results of the transpedicular wedge resection osteotomy. Spine (Phila Pa 1976) 26:2036-2043, 2001

5. Berven SH, Deviren V, Smith JA, Hu SH, Bradford DS: Management of fixed sagittal plane deformity: outcome of combined anterior and posterior surgery. Spine (Phila Pa 1976) 28:1710-1716, 2003

6. Bess RS, Lenke LG, Bridwell KH, Cheh G, Mandel S, Sides B: Comparison of thoracic pedicle screw to hook instrumentation for the treatment of adult spinal deformity. Spine (Phila Pa 1976) 32:555-561, 2007

7. Bianco K, Norton R, Schwab F, Smith JS, Klineberg E, Obeid I, et al: Complications and intercenter variability of three-column osteotomies for spinal deformity surgery: a retrospective review of 423 patients. Neurosurg Focus 36(5):E18, 2014

8. Boachie-Adjei O, Ferguson JA, Pigeon RG, Peskin MR: 
Transpedicular lumbar wedge resection osteotomy for fixed sagittal imbalance: surgical technique and early results.

Spine (Phila Pa 1976) 31:485-492, 2006

9. Bridwell KH, Lewis SJ, Edwards C, Lenke LG, Iffrig TM, Berra A, et al: Complications and outcomes of pedicle subtraction osteotomies for fixed sagittal imbalance. Spine (Phila Pa 1976) 28:2093-2101, 2003

10. Buchowski JM, Bridwell KH, Lenke LG, Kuhns CA, Lehman RA Jr, Kim YJ, et al: Neurologic complications of lumbar pedicle subtraction osteotomy: a 10-year assessment. Spine (Phila Pa 1976) 32:2245-2252, 2007

11. Buttermann GR, Glazer PA, Hu SS, Bradford DS: Anterior and posterior allografts in symptomatic thoracolumbar deformity. J Spinal Disord 14:54-66, 2001

12. Chafetz RS, Vogel LC, Betz RR, Gaughan JP, Mulcahey MJ: International standards for neurological classification of spinal cord injury: training effect on accurate classification. J Spinal Cord Med 31:538-542, 2008

13. Chang KW, Chen YY, Lin CC, Hsu HL, Pai KC: Closing wedge osteotomy versus opening wedge osteotomy in ankylosing spondylitis with thoracolumbar kyphotic deformity. Spine (Phila Pa 1976) 30:1584-1593, 2005

14. Chang KW, Cheng CW, Chen HC, Chang KI, Chen TC: Closing-opening wedge osteotomy for the treatment of sagittal imbalance. Spine (Phila Pa 1976) 33:1470-1477, 2008

15. Cho SK, Bridwell KH, Lenke LG, Yi JS, Pahys JM, Zebala LP, et al: Major complications in revision adult deformity surgery: risk factors and clinical outcomes with 2- to 7-year follow-up. Spine (Phila Pa 1976) 37:489-500, 2012

16. Daubs MD, Lenke LG, Cheh G, Stobbs G, Bridwell KH: Adult spinal deformity surgery: complications and outcomes in patients over age 60. Spine (Phila Pa 1976) 32:22382244, 2007

17. DeWald CJ, Stanley T: Instrumentation-related complications of multilevel fusions for adult spinal deformity patients over age 65: surgical considerations and treatment options in patients with poor bone quality. Spine (Phila Pa 1976) 31 (19 Suppl):S144-S151, 2006

18. Ferreira-González I, Marsal JR, Mitjavila F, Parada A, Ribera A, Cascant P, et al: Patient registries of acute coronary syndrome: assessing or biasing the clinical real world data? Circ Cardiovasc Qual Outcomes 2:540-547, 2009

19. Glassman SD, Hamill CL, Bridwell KH, Schwab FJ, Dimar JR, Lowe TG: The impact of perioperative complications on clinical outcome in adult deformity surgery. Spine (Phila Pa 1976) 32:2764-2770, 2007

20. Hess DR: Retrospective studies and chart reviews. Respir Care 49:1171-1174, 2004

21. Kelly MP, Lenke LG, Shaffrey CI, Ames CP, Carreon LY, Lafage V, et al: Evaluation of complications and neurological deficits with three-column spine reconstructions for complex spinal deformity: a retrospective Scoli-RISK-1 study. Neurosurg Focus 36(5):E17, 2014

22. Kim KT, Lee SH, Suk KS, Lee JH, Jeong BO: Outcome of pedicle subtraction osteotomies for fixed sagittal imbalance of multiple etiologies: a retrospective review of 140 patients. Spine (Phila Pa 1976) 37:1667-1675, 2012

23. Kim KT, Park DH, Lee SH, Suk KS, Lee JH, Park KJ: Partial pedicle subtraction osteotomy as an alternative option for spinal sagittal deformity correction. Spine (Phila Pa 1976) 38:1238-1243, 2013
24. King G, Nielsen R: Why Propensity Scores Should Not Be Used for Matching. (http://gking.harvard.edu/files/gking/ files/psnot.pdf) [Accessed February 2, 2017]

25. Krumholz HM: Registries and selection bias: the need for accountability. Circ Cardiovasc Qual Outcomes 2:517-518, 2009

26. Lenke LG, Fehlings MG, Shaffrey CI, Cheung KM, Carreon L, Dekutoski MB, et al: Neurologic outcomes of complex adult spinal deformity surgery: results of the prospective, multicenter Scoli-RISK-1 Study. Spine (Phila Pa 1976) 41:204-212, 2016

27. Martin RC II, Brennan MF, Jaques DP: Quality of complication reporting in the surgical literature. Ann Surg 235:803813,2002

28. Pannucci CJ, Wilkins EG: Identifying and avoiding bias in research. Plast Reconstr Surg 126:619-625, 2010

29. Smith JS, Klineberg E, Lafage V, Shaffrey CI, Schwab F, Lafage R, et al: Prospective multicenter assessment of perioperative and minimum 2-year postoperative complication rates associated with adult spinal deformity surgery. J Neurosurg Spine 25:1-14, 2016

30. Soroceanu A, Burton DC, Oren JH, Smith JS, Hostin R, Shaffrey CI, et al: Medical complications after adult spinal deformity surgery: incidence, risk factors, and clinical impact. Spine (Phila Pa 1976) 41:1718-1723, 2016

31. Ward RA, Brier ME: Retrospective analyses of large medical databases: what do they tell us? J Am Soc Nephrol 10:429432, 1999

32. Yang BP, Ondra SL, Chen LA, Jung HS, Koski TR, Salehi SA: Clinical and radiographic outcomes of thoracic and lumbar pedicle subtraction osteotomy for fixed sagittal imbalance. J Neurosurg Spine 5:9-17, 2006

\section{Disclosures}

This study received direct support from the Scoliosis Research Society, AOSpine International, and Norton Healthcare. Funds were paid to institutions based upon enrollment.

\section{Author Contributions}

Conception and design: Kelly, Lenke, Shimer. Acquisition of data: Kelly, Lenke, Lewis, Ames, Fehlings, Schwab, Shimer. Analysis and interpretation of data: Kelly. Drafting the article: Kelly. Critically revising the article: Lenke, Godzik, Pellise, Shaffrey, Smith, Lewis, Ames, Carreon, Schwab, Shimer. Reviewed submitted version of manuscript: Kelly, Godzik, Smith, Fehlings. Approved the final version of the manuscript on behalf of all authors: Kelly. Statistical analysis: Kelly.

\section{Supplemental Information}

\section{Previous Presentations}

A portion of this study was presented at the 48th Annual Meeting of the Scoliosis Research Society, Lyon, France, September 18-21, 2013.

\section{Correspondence}

Michael P. Kelly, Department of Orthopedic Surgery, Washington University School of Medicine, 660 South Euclid Ave., Box 8233, St. Louis, MO 63110. email: kellymi@wudosis.wustl.edu. 